\title{
Isolation and functional characterization of exopolysaccharide from Lactobacillus plantarum S123 isolated from traditional Chinese cheese
}

\author{
Muhammad Saleem \\ Shenzhen University \\ Samiullah Malik \\ Shenzhen University \\ Hafiza Mahreen Mehwish \\ Shenzhen University \\ Muhammad Waqas Ali \\ Shenzhen University \\ Nazim Hussain \\ Punjab University \\ Mohsin Khurshid \\ Government College University Faisalabad \\ Muhammad Shahid Riaz Rajoka ( $\nabla$ shahidrajoka@yahoo.com ) \\ Tohoku University, Japan

\section{Yougen Chen} \\ Shenzhen University
}

\section{Research Article}

Keywords: Exopolysaccharide, Functional food, anti-oxidant activity, Lactobacillus

Posted Date: March 22nd, 2021

DOI: https://doi.org/10.21203/rs.3.rs-301834/v1

License: (1) (1) This work is licensed under a Creative Commons Attribution 4.0 International License. Read Full License 


\section{Abstract}

Presently, exopolysaccharide (EPS), due to its exceptional biological features is used as an efficient biopolymer. Therefore, the present study aimed is the EPS production by Lactobacillus Plantarum S123, its biopotential investigation and technological functional characterization. The results of microscopic examination suggested that the S123 EPS has a major portion of amorphous spongy like structure with partial crystalline nature. The FTIR and NMR results suggested that the S123 EPS consists on carbonyl and hydroxyl group respectively. Furthermore, the results of biopotential investigation suggested that the S123 EPS exhibited excellent antimicrobial activity against Gram's positive $(7.2 \mathrm{~mm})$ and Gram's negative bacteria $(11.5 \mathrm{~mm}), \mathrm{DPPH}$ radical scavenging activity $(>65 \%)$, water holding capacity $(326.6 \pm 0.5 \%)$, oil holding capacity $(995.3 \pm 0.2 \%)$, flocculation $(89.5 \pm 0.6 \%)$, and emulsifying $(80.1 \pm 1.1 \%)$ activities. Overall, the present results suggested that due to highly porous structure, efficient biotechnological potential the S123 EPS from Lactobacillus plantarum S123 can be used in the functional food product.

\section{Full Text}

Due to technical limitations, full-text HTML conversion of this manuscript could not be completed. However, the latest manuscript can be downloaded and accessed as a PDF.

\section{Figures}


(A)

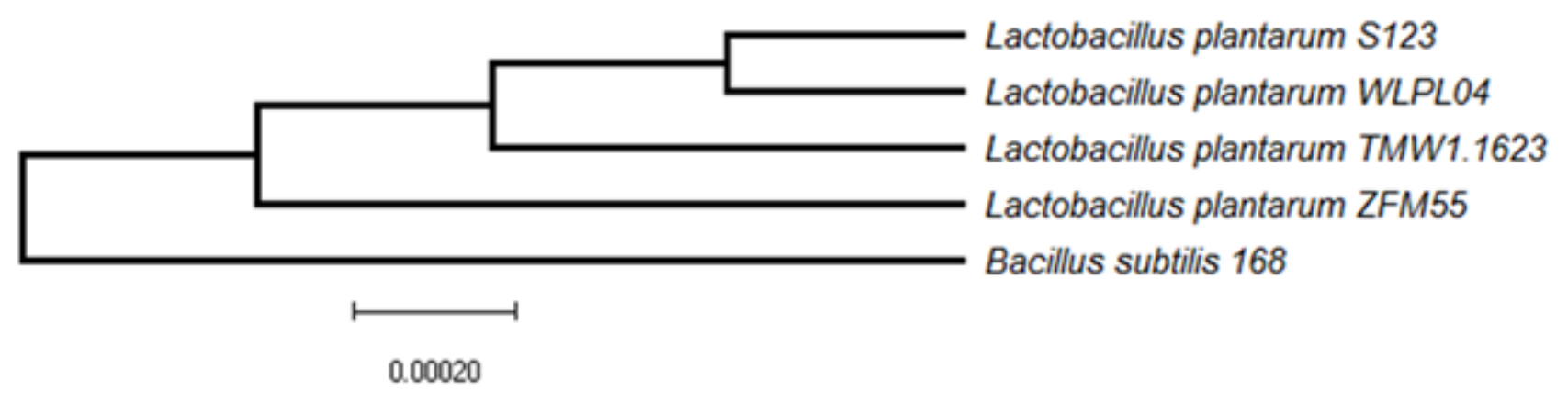

(B)

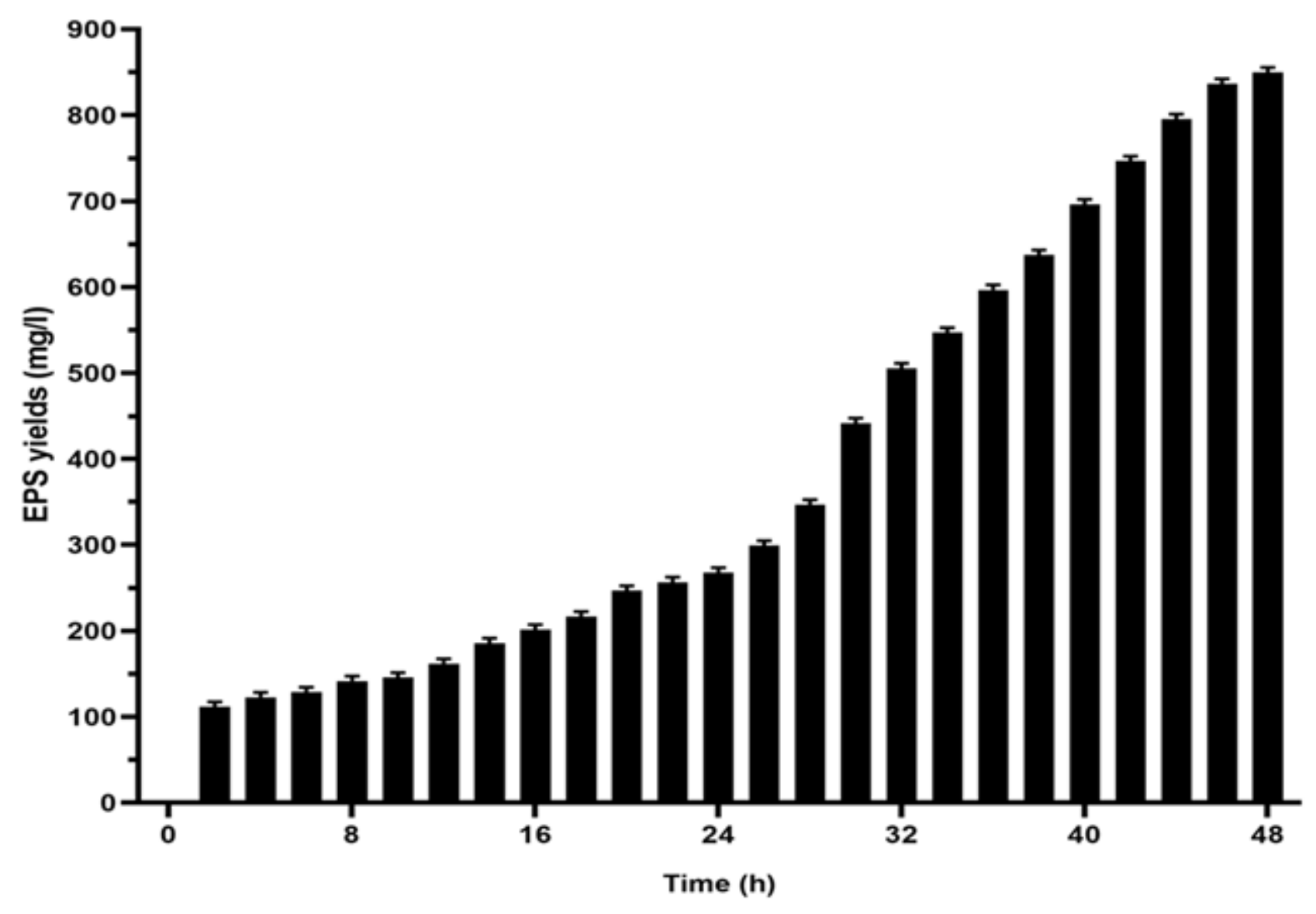

Figure 1

(A) Phylogenetic tree, (B)Production kinetic curve of EPS-producing Lactobacillus plantarum S123 EPS at $37^{\circ} \mathrm{C}$ up to $48 \mathrm{~h}$. The results are presented as three independent analysis (mean $\pm \mathrm{SD}, \mathrm{n}=3$ 


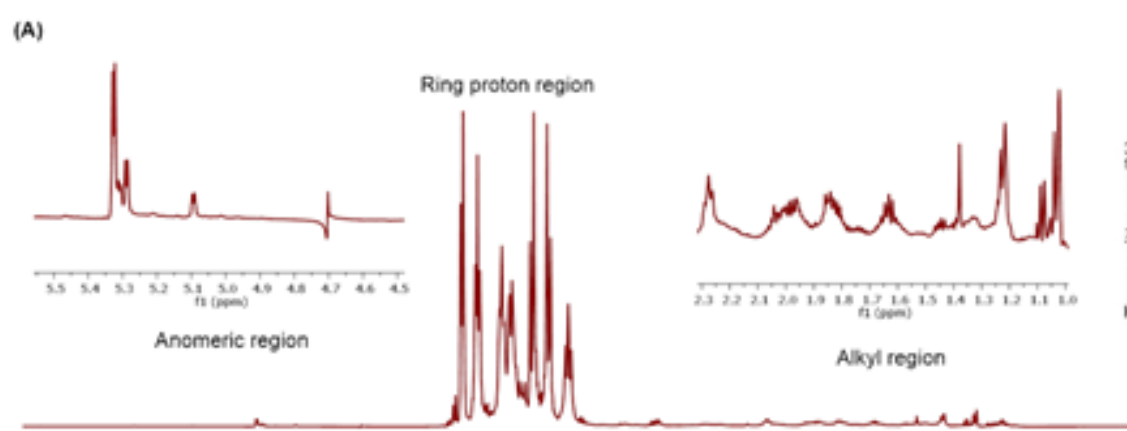

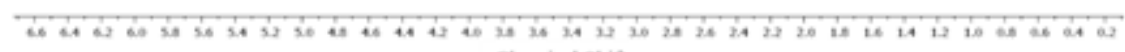

(B)

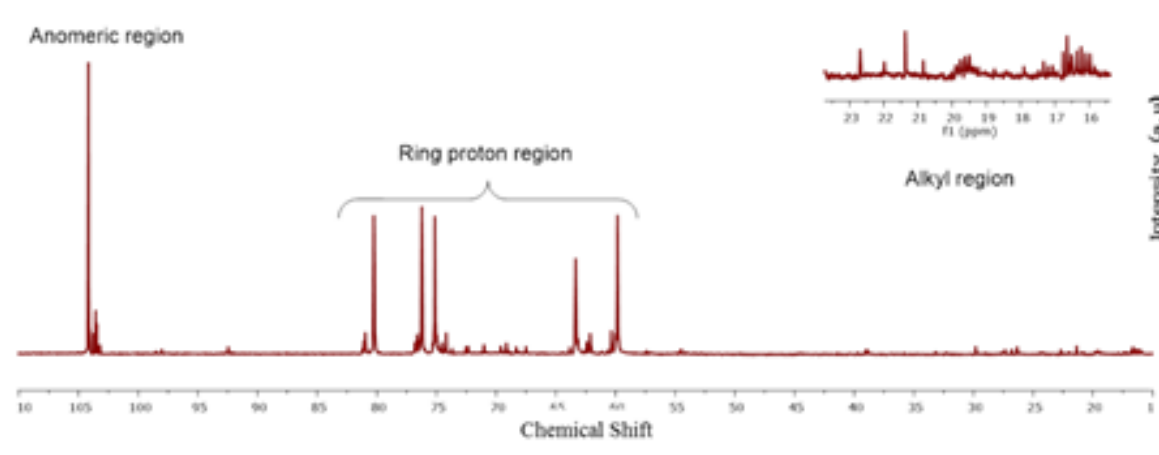

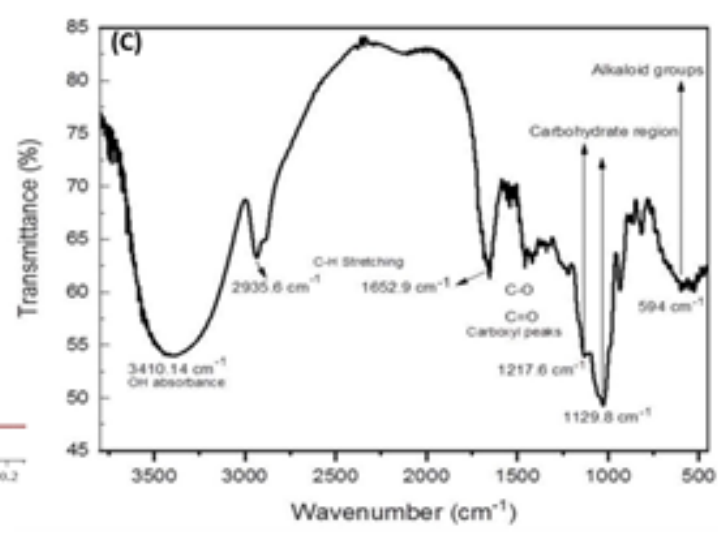

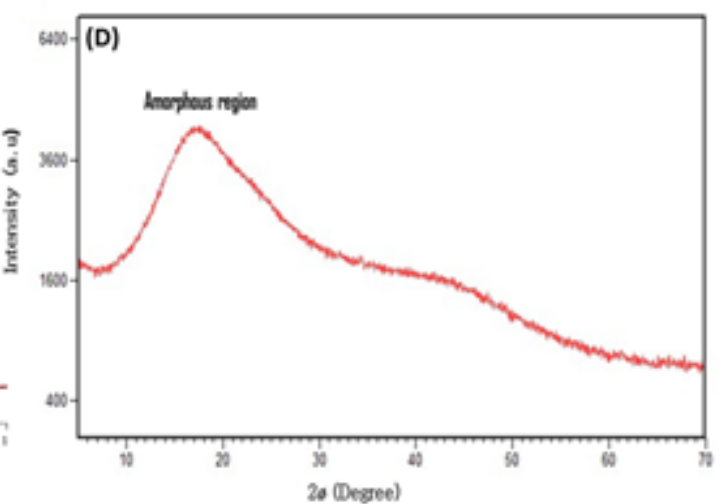

Figure 2

1H Spectra (A), and 13C Spectra (B) of isolated S123 EPS (C) FTIR spectra of isolated S123 EPS with important functional peaks and (D) XRD analysis showing major amorphous region of the isolated S123 EPS 

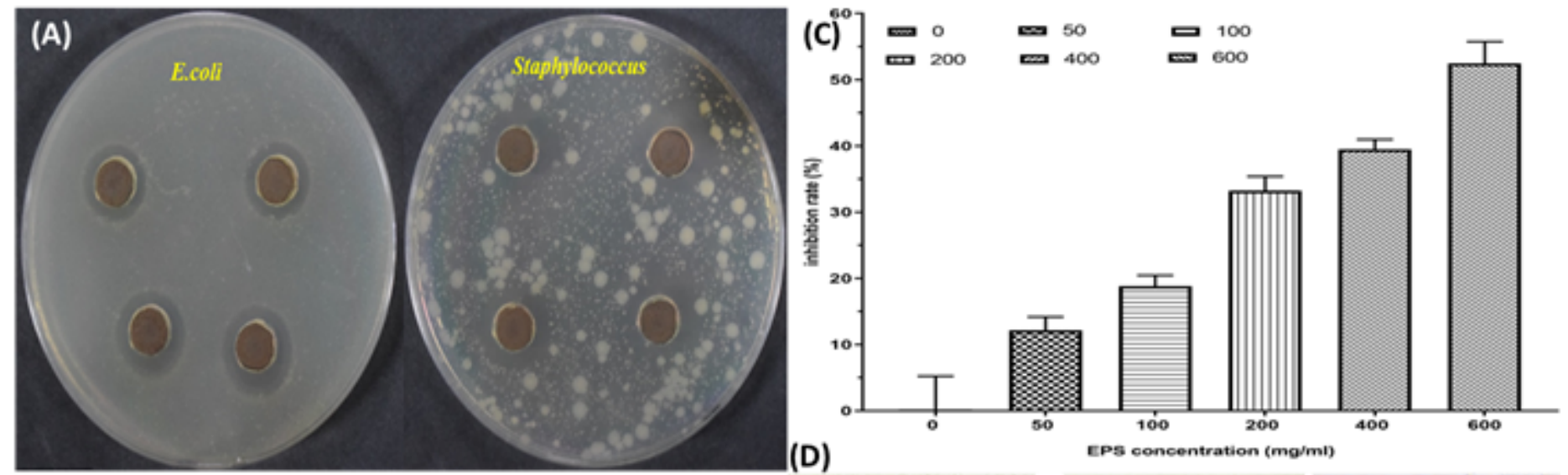

(B)

$0 \mathrm{mg} / \mathrm{m}$
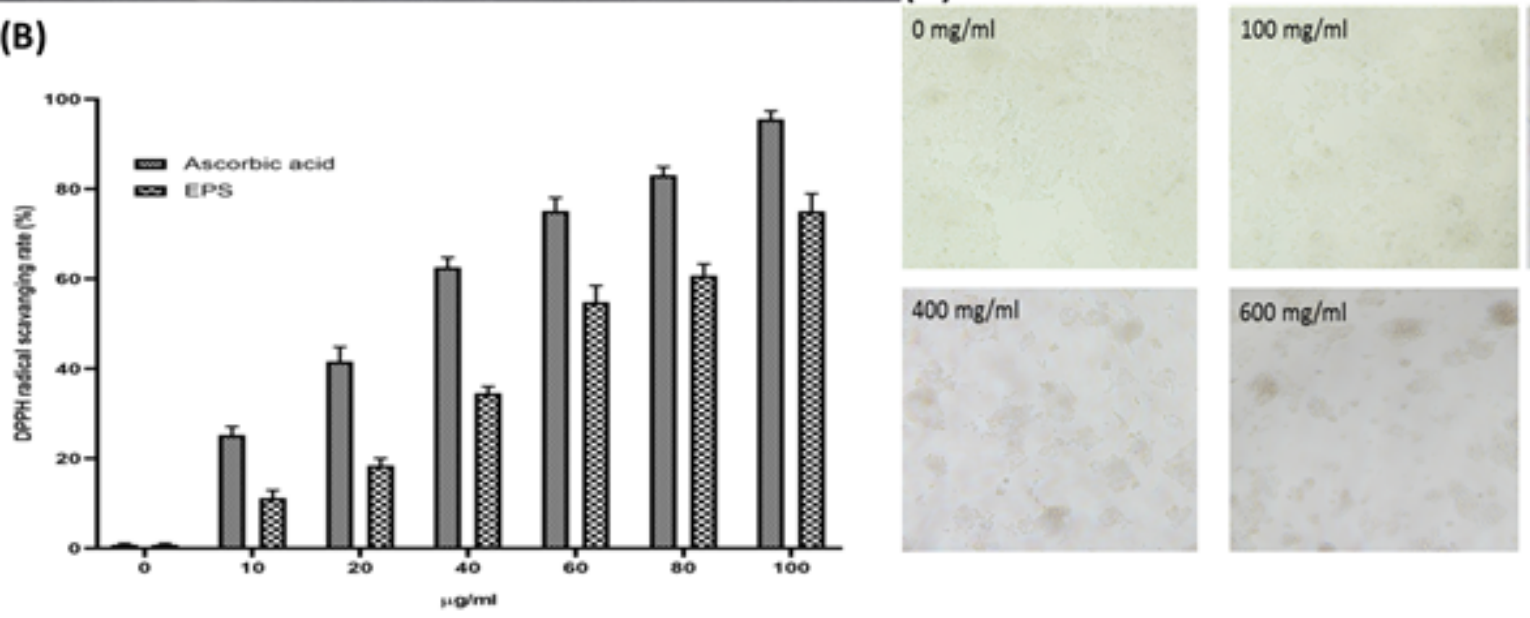

$200 \mathrm{mg} / \mathrm{ml}$

Figure 3

(A) Antimicrobial activity of S123 EPS against pathogenic bacterial species tested by well diffusion assay, (B) Scavenging activity of S123 EPS samples on hydroxyl radical DPPH radical, (C) Inhibition rate flow chart along with S123 EPS concentration and (D) Cytotoxicity assay of S123 EPS on HT-29 cell 